Case report

\title{
Leser-Trélat sign presenting in a patient with ovarian cancer:
}

a case report

\author{
Edwin Bölke ${ }^{*}$, Peter Arne Gerber ${ }^{2}$, Matthias Peiper ${ }^{3}$, \\ Wolfram Trudo Knoefel ${ }^{3}$, Mathias Cohnen ${ }^{4}$, Christiane Matuschek ${ }^{1}$, \\ Wilfried Budach ${ }^{1}$, Rainer Engers ${ }^{5}$ and Stephan Gripp ${ }^{1}$
}

\footnotetext{
Addresses: ${ }^{1}$ Department of Radiation Therapy and Radiation Oncology, University of Düsseldorf, Moorenstrasse 5, 40225 Düsseldorf, Germany ${ }^{2}$ Department of Dermatology, University of Düsseldorf, Moorenstrasse 5, 40225 Düsseldorf, Germany

${ }^{3}$ Department of Surgery, University of Düsseldorf, Moorenstrasse 5, 40225 Düsseldorf, Germany

${ }^{4}$ Institute of Diagnostic Radiology, University of Düsseldorf, Moorenstrasse 5, 40225 Düsseldorf, Germany

${ }^{5}$ Department of Pathology, University of Düsseldorf, Moorenstrasse 5, 40225 Düsseldorf, Germany

Email: EB* - boelke@med.uni-duesseldorf.de; PAG - PeterArne.Gerber@uni-duesseldorf.de; MP - Peiper@med.uni-duesseldorf.de; WTK - knoefel@med.uni-duesseldorf.de; MC - cohnen@med.uni-duesseldorf.de; CM - matuschek@med.uni-duesseldorf.de; WB - wilfried.budach@med.uni-duesseldorf.de; RE - engers@med.uni-duessldorf.de; SG - gripp@uni-duesseldorf.de

* Corresponding author
}

Received: 28 February 2008 Accepted: 9 February 2009 Published: 23 July 2009

Journal of Medical Case Reports 2009, 3:8583 doi: 10.4076/1752-1947-3-8583

This article is available from: http://casesjournal.com/casesjournal/article/view/8583

(C) 2009 Bölke et al.; licensee Cases Network Ltd.

This is an Open Access article distributed under the terms of the Creative Commons Attribution License (http://creativecommons.org/licenses/by/3.0),

which permits unrestricted use, distribution, and reproduction in any medium, provided the original work is properly cited.

\begin{abstract}
Introduction: Seborrheic keratoses are very common findings in elderly patients. However, a sudden onset and dramatic increase in the number and size of these benign lesions deserves special attention, since this may represent the Leser Trélat sign, a rare paraneoplastic cutaneous syndrome.

Case presentation: A 92-year-old female presented to our clinic with multiple eruptive seborrheic keratoses, which had dramatically increased in size and number over the past two years. A diagnostic work-up revealed an ovarian carcinoma. Hence, cutaneous findings in our patient were consistent with the diagnosis of the Leser-Trélat sign.

Conclusion: The Leser-Trélat sign may coincide with the diagnosis of occult cancer or follow or precede it by months or years. Practitioners should take cases of eruptive seborrheic keratoses seriously and perform thorough patient examinations.
\end{abstract}

\section{Introduction}

Seborrheic keratoses are very common findings in elderly patients. Yet, a sudden onset and dramatic increase in the number and size of these benign lesions deserves special attention, since these may represent a rare paraneoplastic syndrome. Seborrheic keratoses may coincide with the diagnosis of occult cancer or follow or precede it by months or years. This complex is referred to as the Leser-Trélat sign.

\section{Case presentation}

A 92-year-old woman presented to our clinic with multiple, tan to black coloured skin eruptions with rough, warty 
or greasy surfaces, consistent with the diagnosis of multiple seborrheic keratoses. The lesions had dramatically increased in size and numbers over the past 2 years (Panel $1 \mathrm{~A}$ and $\mathrm{B}$ ). Moreover, the patient reported a 2-month history of abdominal pain and weight loss. Laboratory examinations revealed elevated CA 125 plasma levels of $500 \mathrm{U} / \mathrm{ml}$. Clinical examination showed signs of mild ascites. Additional staging examinations, including diagnostic abdominal ultrasound and computed tomography (CT), revealed a distinctive, partly necrotic tumor $(8 \mathrm{~cm}$ by $10 \mathrm{~cm}$ in diameter), originating from the left ovary and occupying the pelvis. The tumor mass was accompanied by signs of peritoneal carcinomatosis (Panel 1C). A posterior exenteration with double sided ovariectomy, hysterectomy, rectum resection and Hartmann's procedure was performed. Histopathological evaluation revealed a poorly differentiated serous papillary adenocarcinoma of the right (Panel 2A) and left (Panel 2B) ovary, infiltrating the colon, the small intestine, both Fallopian tubes and the uterus (original magnifications: A, ×40; B, ×100).

Cutaneous findings in our patient were consistent with the diagnosis of the Leser-Trélat sign. This rare paraneoplastic cutaneous syndrome is defined as the sudden onset and dramatic increase in the number and size of seborrheic keratoses as a result of cancer [1]. Skin lesions are most often observed on the back and chest, followed by the extremities, face and abdomen [1]. In almost 50 percent of affected patients the Leser-Trélat sign is accompanied by pruritus, whereas a paraneoplastic acanthosis nigricans is evident in 35 percent of the cases [2-4]. Predominant cancer entities in patients with the Leser-Trélat sign are gastrointestinal adenocarcinomas (stomach, liver, pancreas, colon, rectum) and lymphoproliferative disorders
$[1,4,5]$. Moreover, the syndrome has been reported in cases of neoplasias of the breast, the lung and the urinary tract $[1,6]$. However, manifestations of the Leser-Trélat sign in gynaecologic malignancies and in particular in cases of ovarian cancer, as in our patient, are rare $[3,7]$.

Pathogenetically, eruptive cutaneous paraneoplastic disorders are suspected to be induced directly by tumorsecreted growth factors [1]. Accordingly, various authors have described an association of the Leser-Trélat sign with increased levels of transforming growth factor alpha (TGF- $\alpha$ ), insulin-like growth factor, epidermal growth factor (EGF) or an increased expression or activity of the epidermal growth factor receptor (EGFR) [1,8-10]

\section{Conclusion}

Whereas seborrheic keratoses are very common findings in elderly patients, the eruptive appearance of a number of these benign skin tumors requires further examination. Since these lesions may coincide with the diagnosis of occult cancer, or follow or precede it by months or years, practitioners should perform a thorough examination including taking a complete patient history, physical examination, routine blood tests, chest radiography, abdominal ultrasound or computed tomography (CT), as well as mammography and a Papanicolaou smear test in women and prostate-specific antigen testing in men. With regard to the high incidence of gastrointestinal neoplasias, additional endoscopic analyses (esophagogastroduodenoscopy and colonoscopy) should be considered [4].

In our case the patient was treated with surgery and at the time of writing is receiving palliative chemotherapy with carboplatin.

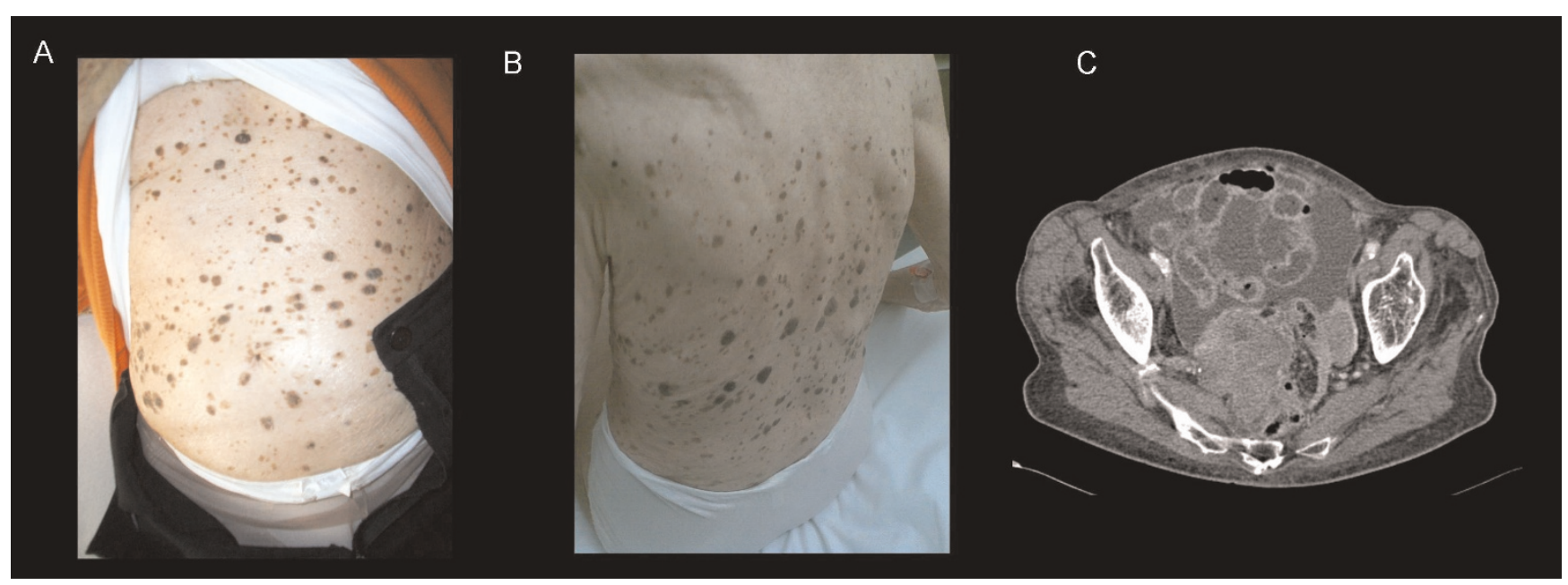

Figure I. (A) and (B) Widespread seborrheic keratoses. (C) Computed tomography scan showing a necrotic tumor accompanied by signs of peritoneal carcinomatosis. 

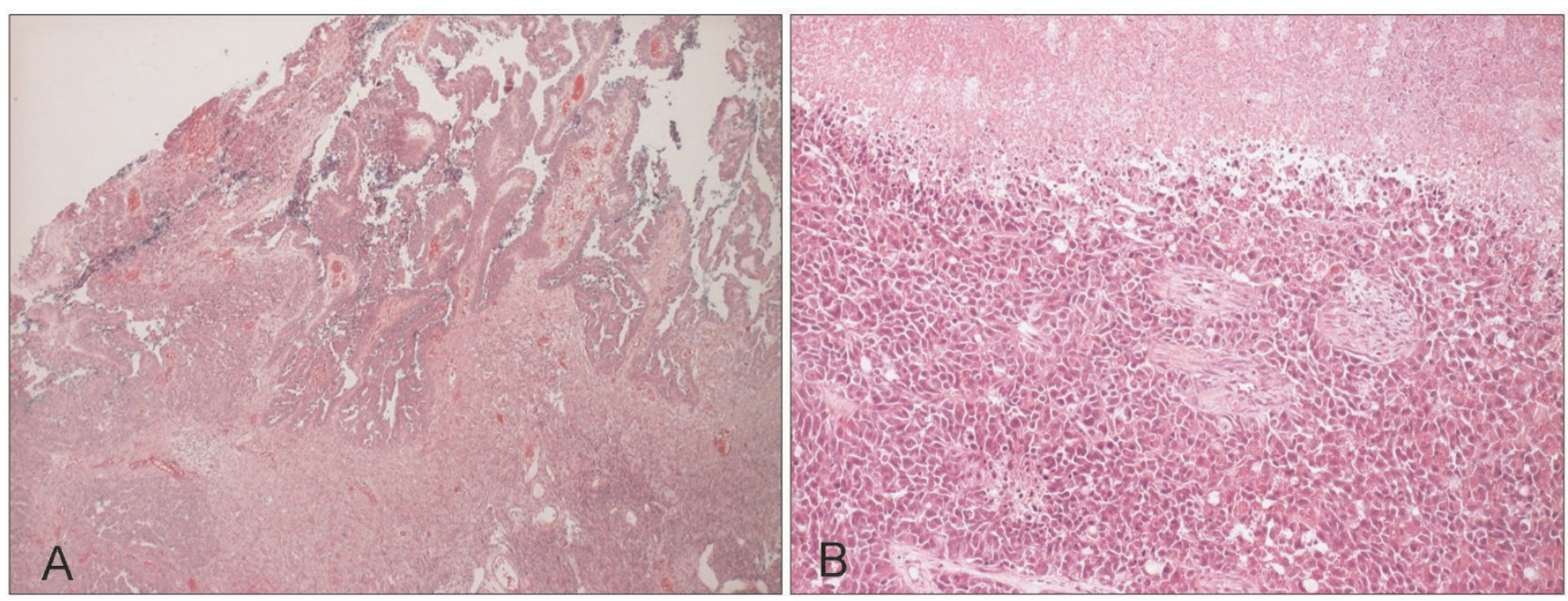

Figure 2. Histopathological evaluation revealing a poorly differentiated serous papillary adenocarcinoma of the right (A) and left (B) ovary, infiltrating the colon. Original magnifications: A, ×40; B, ×100.

\section{Authors' contributions}

EB and PAG analyzed and interpreted the patient data. RE performed the histological examination. All authors read and approved the final manuscript.

\section{Consent}

Written informed consent was obtained from the patient for publication of this case report and accompanying images. A copy of the written consent is available for review by the Editor-in-Chief of this journal.

\section{Competing interests}

The authors declare that they have no competing interests.

\section{References}

I. Schwartz RA: Sign of Leser-Trelat. J Am Acad Dermatol 1996, 35:88-95.

2. Holdiness MR: On the classification of the sign of Leser-Trelat. J Am Acad Dermatol 1988, 19:754-757.

3. Ashour AA, Verschraegen CF, Kudelka AP, Kavanagh JJ: Paraneoplastic syndromes of gynecologic neoplasms. J Clin Oncol 1997, 15:1272-1282.

4. Kurzrock R, Cohen PR: Cutaneous paraneoplastic syndromes in solid tumors. Am J Med 1995, 99:662-67I.

5. Kilickap S, Yalcin B: Images in clinical medicine. The sign of LeserTrelat. N Engl J Med 2007, 356:2 I84.

6. Heaphy MR Jr, Millns JL, Schroeter AL: The sign of Leser-Trelat in a case of adenocarcinoma of the lung. J Am Acad Dermatol 2000, 43:386-390.

7. Kebria MM, Belinson J, Kim R, Mekhail TM: Malignant acanthosis nigricans, tripe palms and the sign of Leser-Trelat, a hint to the diagnosis of early stage ovarian cancer: a case report and review of the literature. Gynecol Oncol 2006, I 01:353-355.

8. Horiuchi Y, Katsuoka K, Takezaki S, Nishiyama S: Study of epidermal growth activity in cultured human keratinocytes from peripheral-blood lymphocytes of a patient with Sezary syndrome associated with the Leser-Trelat sign. Arch Dermatol Res 1985, 278:74-76.

9. Ellis DL, Kafka SP, Chow JC, Nanney LB, Inman WH, McCadden ME, King LE Jr: Melanoma, growth factors, acanthosis nigricans, the sign of Leser-Trelat, and multiple acrochordons. A possible role for alpha-transforming growth factor in cutaneous paraneoplastic syndromes. N Engl J Med 1987, 317:1582-1587.

10. Benn JJ, Firth RG, Sonksen PH: Metabolic effects of an insulin-like factor causing hypoglycaemia in a patient with a haemangiopericytoma. Clin Endocrinol (Oxf) 1990, 32:769-780.

\section{Do you have a case to share?}

Submit your case report today

- Rapid peer review

- Fast publication

- PubMed indexing

- Inclusion in Cases Database

Any patient, any case, can teach us something

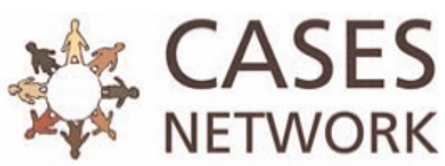

www.casesnetwork.com 